\title{
SUSTAINABILITY METRICS: MEASURING SUSTAINABLE DEVELOPMENT FOR TOURISM
}

\author{
Elma Šatrović ${ }^{1}$ \\ Ensar Šehić
}

\begin{abstract}
Sustainable tourism is defined as tourism that improves the quality of life of the host community, providesa high quality of experience for the visitors and maintains the quality of the environment on which both the host community and the visitor depend. In order to measure sustainability in tourism researchers use set of subjective and objective indicators. However, the analysis conducted in this paper shows both types of indicators have some weaknesses, so there is a need to use other measurement tools. As far as we know, there have been no studies of the three most commonly used sustainability measurement tools (AIChEBRIDGESworks Metrics, GEMI Metrics Navigator ${ }^{\mathrm{TM}}$ and IChemE Sustainability Metrics) in tourism. Our study is the first one to deal with these measurement tools. The aim of this paper is to describe most commonly used sustainability measurement tools; their special requirements for tourism and to answer the question how tourism contributes to sustainable development. Analysis shows that tourism contributes to sustainable development primarily through community-driven tourism development; minimization of negative social and cultural impacts; optimization of economic benefits; protection of physical and man-made resources, ethics, policy, standards; visitor satisfaction, maintaining destination attractiveness, use of proper tools and full community participation. Methodology that is used is comparative analysis of three most common sustainability measurement tools. Results obtained by comparative analysis indicate thatAIChEBRIDGESworks Metrics, GEMI Metrics Navigator ${ }^{\mathrm{TM}}$ and IChemE Sustainability Metrics have some common requirements for different businesses. However, requirements for tourism are very strict since it is considered as non-community based business, short-term planning, no protection of natural and human resources, huge economic benefits provider and business that has non-ethnical attitude towards environment. Conclusion states that taking into consideration the weaknesses of all analyzed tools, there is a need for further development of sustainability measurement tools in tourism.
\end{abstract}

Keywords: conventional tourism, sustainable development, sustainability measurement tools, sustainable tourism, Triple Bottom Line.

\section{INTRODUCTION}

Sustainable development can be defined as"developmentthat meets the needs of the present without compromising the ability of future generations to meet their own needs" (Székely and Knirsch 2005). Today, humanity faces a lot of challenges ofcontributing to sustainable development. Natural resources have been degraded, gap between rich and poor has widened dramatically, the earth is overpopulated, environmental pollution increases with every passing year and causesirreparable damage to the earth etc.

It is important to point out that the challenge of contributing to sustainability requires the commitment and active participation of all members of society, including businesses. This is why this paperexplores how tourism contributes to sustainable development. The aim of

\footnotetext{
${ }^{1} \mathrm{PhD}$ candidate,School of Economics and Business, University of Sarajevo, Sarajevo, Bosnia and Herzegovina.

${ }^{2}$ Assistant Professor,School of Economics and Business, University of Sarajevo, Sarajevo, Bosnia and Herzegovina.
} 
this paper is to describe most commonly usedsustainability measurement tools; their special requirements fortourismand to answer the question how tourismcontributes to sustainable development.Initially, it is important to emphasize that during last decades, as a response to developmental ills associated with conventional mass tourism various forms of tourism (e.g. green tourism, ecotourism) have beengaining prominence as more benign alternativesthat help increase awareness of the negative impactsof tourism and have raised consequent calls for impactassessment studies.

This paper starts with introductory remarks. Inthe second part the definition of sustainable development is given. Third part explainssustainable tourism. Forth part talks about requirements of sustainability metrics; methodologies that are used to identify most appropriate tool for particular company and gives overview of sustainability measurement tools. Paper ends with concluding remarks.

\section{LITERATURE REVIEW}

Until the late 1970s, in many regions and countries, tourism was considered a business that brings more benefits with fewer financial resources. However it is considered as business that causes irreparable damage on human society and nature (Chris Choi and Sirakaya, 2005). Expectations of society at large are forcing tourism companies to refashion the conventionaltourism development framework and to meet the needs ofnew environmentalism standards while sustaining an optimallevel of socioeconomic benefits.

The Berlin Declaration(1997) made a strong normative point by suggesting thattourism should benefit local communities, strengthens the local economy, employsthe local workforce, and wherever ecologically sustainable,uses local materials, local agricultural products, and traditionalskills. Policies and legislation and other mechanisms should be introduced to ensure the flow of benefits to localcommunities. With the establishment of special journals related to sustainability issues and the proliferation of sustainable-tourismrelated articles the discourse on sustainable tourism has moved to the development of tools that are necessary to measure and evaluate various aspects of sustainable tourism (Chris Choi and Sirakaya, 2005).

An area that draws considerable attention is indicatorresearch. Indicators are usually used to measure and monitor development progress in communities. Mostly, researchers rely on objective indicators in order to measure developmental progress. According to Rossi and Gilmartin (1980) objective indicators refer to "quantitative counts of behaviors and conditions associated with a given situation". The drawbacks of these indicators include weaknesses in assessing all aspects of the development progress since there are limits in observation and aggregation (Veenhoven, 2001). On the other hand subjective indicators reflect residents' emotions, personal evaluations, attitudes etc. Chris Choi and Sirakaya (2005) indicate that mostly researchers use objective indicators and point out the importance of subjective. However, the combination of both indicators would mitigate weaknesses of both indicators and provide better information for decision makers.

In addition it is important to emphasize that in an era when sustainability seems to be emerging as a major social paradigm, tools developed solely to measure perceptions of positive/negative impacts of tourism within the traditional conceptual works may be insufficient (Hoff 1998). So, objective and subjective indicators that are used in 
(Veenhoven, 2001; Rossi and Gilmartin, 1980; McIntyre, 1993; Sharpley and Sharpley, 1997 and McGahey, 1996) are not considered appropriate. This is why some authors try to develop and test innovative frameworks, new scales and measurement tools (Chris Choi and Sirakaya, 2005). However, all of these tools have some drawbacks. Taking into consideration the importance of sustainability measurement in all businesses, different institutions have developed sustainability measurement tools. According to the authors best knowledge there are no papers that analyze applicability of the three most commonly used sustainability measurement tools (AIChEBRIDGESworks Metrics, GEMI Metrics Navigator $^{T M}$ andIChemE Sustainability Metrics) in tourism. This motivates authors to conduct comparative analysis of requirements of aforementioned measurement tools for tourism.

\section{THE DEFINITION OF SUSTAINABLE DEVELOPMENT}

The most commonly used definition of sustainable development is published in 1987 and states that: "Sustainable development is development that meets the needs of the present without compromising the ability of future generations to meet their own needs" (Székely and Knirsch, 2005). The concept of sustainable development is simple enough:the natural resources of the earth are limited; they are being used disproportionately by a minority of people living in wealthy nations, thus creating intra-generational inequity. The rate of use of these resources is ever-increasing, thus depriving the future generations of a living standard comparable to that of the present, and creating inter-generational inequity (Sikdar, 2003).

The confusion and conflict about the meaning of sustainable development still exits. However, sustainable development is thought to be a balance between economic development, societal equity and environmental protection (Majumdar et al., 2009). In some business circles this is referred to as the Triple Bottom Line (TBL) (Sikdar 2003; Fig. 1).

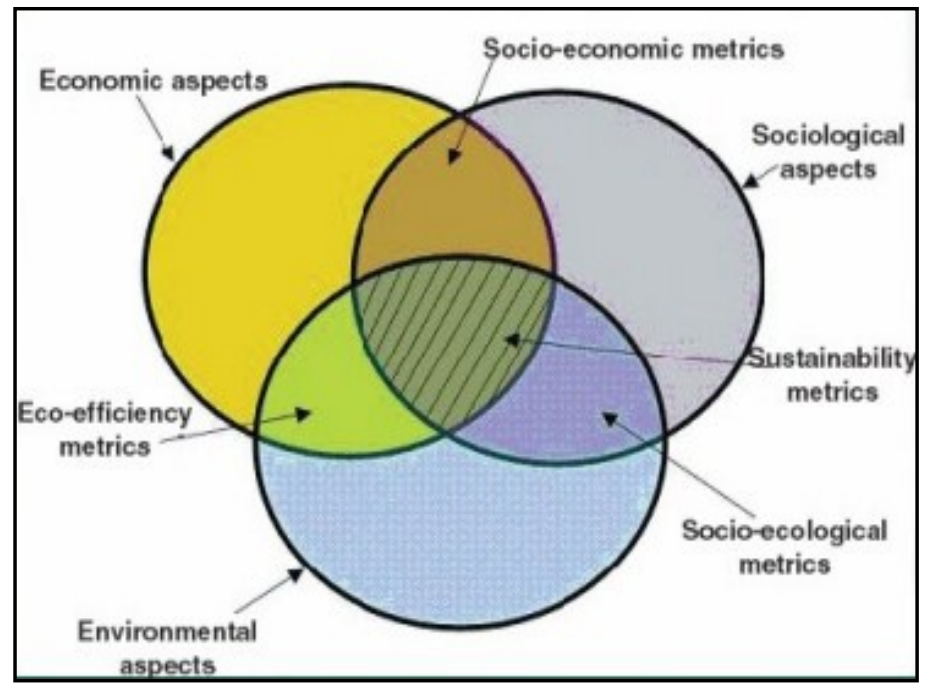

Fig. 1. Triple Bottom Line concept

Source: Majumdar et al. (2009) 
The contribution to sustainable development requires the commitment and active participation of all members of society, including businesses. In the case of businesses, sustainability includes the implementation of strategies and activities that meet the needs of business itself and its stakeholders while protecting and sustaining natural resources (Majumdar et al., 2009). Thanks to the growing pressure from governments and other members of society, large companies have started developing initiatives to contribute sustainable development nowadays.

In 1998 John Elkingtom proposed the Triple Bottom Line reporting. He emphasized that economic performance is most commonly reported sustainability sphere and represents survival basis for businesses and shareholders. Expectations of society at large are forcing companies to be greener and point out the importance of environmental performance. However, third performance (social) is the least common in businesses reports as well as in academic literature (Székely and Knirsch, 2005).

In addition three critics of TBL reporting are provided. The first critic indicates that environmental impacts can be eliminated by economic. The second argues that the comparison of environmental and social sphere with economic in monetary terms is unfair while the third indicates that it is common for business to report and measure ecoefficiency which is the combination of environmental and economic performance and operations (Majumdar et al., 2009). However, socio-economic (interactions between social and economic spheres - Fig. 1) as well as socio-ecological (interactions between social and environmental spheres) are generally ignored.

\section{SUSTAINABLE TOURISM}

The sustainable tourism paradigm seeks to strike abalance between the traditional "utility paradigm" and itsderivative, "social exchange theory," which focuses onthe tradeoff between economic costs and benefits, and thenew environmental paradigm (NEP), which concentrates onconservation/preservation of all resources and enhancementof the wellbeing of communities during generations to come(Rowe, 1992). For the purpose of this paper, sustainabletourism is defined as tourism thatimproves "the quality of life of the host community, providesa high quality of experience for the visitors and maintainsthe quality of the environment on which both the host communityand the visitor depend" (McIntyre, 1993). The aim of sustainable tourism is to mitigate the negative impacts of conventional masstourism.

Sustainable tourism was born out of hopes and desires for a better future and concerns and fears about conventional tourism development and has been popularized as the best of the known alternatives. Sustainable tourism aims to provide a new way of developing destinations that can establish relationship between tourism and environment, society, culture, and politics (Sharpley and Sharpley, 1997).

The most common questions in relation between sustainable development and tourism are:

- What are appropriate measurement tools of Triple Bottom Line ideas?

- What are differences between sustainability measurement tools for tourism and other businesses?

- How tourism contribute to sustainable development? 
According to Chris Choi and Sirakaya (2005) tourism can contribute sustainable development through: community-driven tourism development; minimization of negative social and cultural impacts; optimization of economic benefits; protection of physical and man-made resources, ethics, policy, standards; visitor satisfaction, maintaining destination attractiveness, use of proper tools and full community participation.

Defenders of conventional tourism argue that one of the main goals of tourism development is to maximize economic benefits (McGahey, 1996). However, advocates of sustainable tourism indicate that environmental as well as social aspects of sustainable development have to be considered as well.

\section{SUSTAINABILITY MEASUREMENT TOOLS FOR TOURISM}

Companies that aim to contribute to sustainable development consider measuring progress as critical to success. Morris et al. (1998) emphasize that: British Petroleum, IKEA, Interface, and Royal Dutch/Shell explore not only reasons and ways for achieving sustainable development goals but also the measurement tools. Further, this paperprovides anoverview of: requirements of sustainability metrics; methodologies that are used to identify the most appropriate tool for particular company and gives overview of sustainability measurement tools for tourism.

\section{Requirements of sustainability metrics}

According to Majumdar et al. (2009) roles of metrics are to: address specific issues relevant to the business; contain features/methods by which these issues can be measured and allow users to set realistic goals and to measure progress towards these goals.Morris et al. (1998) indicates the ideal metrics will be this that consolidates progress across all three dimensions of TBL.However, the biggest challenge in developing sustainability metrics is the organization of information in a way that best fits decision-making in terms of sustainable development (Székely and Knirsch, 2005).

Companies will be able to use sustainable development metrics effectively if developed metrics satisfies following requirements: companies have to be able to set goals; to develop action plans; to support the decision-making, adapt and implement changes. Companies need also to be able to measure progress; to compare the achieved performance with alternatives; metrics has to be user-friendly, flexible and adaptable to different stakeholders (Majumdar et al., 2009). If companies use metrics that satisfy aforementioned requirements, they are allowed to set goals, take actions, set benchmarks and analyze actions towards achieving goals.

\section{Methodologies}

In order to identify the most suitable tool for particular company, different methodologies have been adopted. The complexity of methodologies has evolved over time. In this paper Bellagio framework is presented. In November 1996, an international group of measurement practitioners and researchers from five continents came together in Bellagio, Italy to monitor progress towards practices of sustainable development and to summarize insights from practice (Hardi and Zdan, 1997). This monitoring resulted in principles that serve as guidelines for the whole of the assessment process including the design and choice of indicators, communication of the resultand their interpretation (Hardi and Zdan, 1997; 
Tab.1). These principles should be applied together in order to identify the tool that best fits observed company. The conceptual model of Bellagio framework is presented in Fig.2:

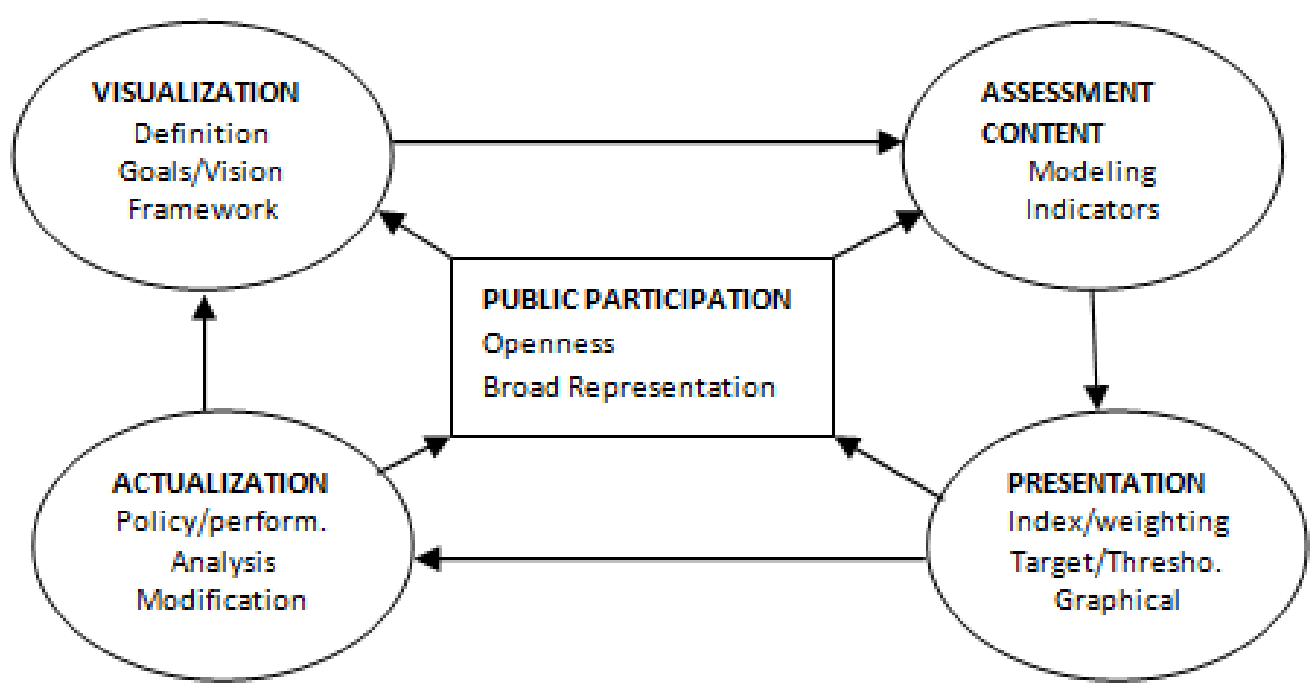

Fig.2. Conceptual model of Bellagio framework

Source: Becker(2004), cited in Majumdar et al. (2009)

Tab.1 summarizes Bellagio principles and assessment of progress:

Tab. 1. The summary of Bellagio principles and assessment of progress

\begin{tabular}{|c|c|c|}
\hline Principle & Code & Assessment of progress \\
\hline Guiding Vision and Goals & BP1 & $\begin{array}{l}\text { Should be guided by a clear vision of sustainable development and goals } \\
\text { that define that vision. }\end{array}$ \\
\hline Holistic Perspective & $\mathrm{BP} 2$ & $\begin{array}{l}\text { Should include review of the whole system; analyze changes and } \\
\text { consider the well-being of social, ecological, and economic sub-systems; } \\
\text { consider positive and negative consequences of human and ecological } \\
\text { systems. }\end{array}$ \\
\hline Essential Elements & BP3 & $\begin{array}{l}\text { Should consider equity and disparity within the current population; } \\
\text { present and future generations, dealing with: resource use, over- } \\
\text { consumption and poverty, human rights; consider the ecological } \\
\text { conditions; consider economic development and other activities that } \\
\text { contribute to social well-being. }\end{array}$ \\
\hline Adequate Scope & BP4 & $\begin{array}{l}\text { Should adopt a time horizon that spans both human and ecosystem time } \\
\text { scales; includelong distance impacts on people and ecosystems; build on } \\
\text { historic and current conditions to anticipate future conditions. }\end{array}$ \\
\hline Practical Focus & BP5 & $\begin{array}{l}\text { Should be based on an explicit set of categories or an organizing } \\
\text { framework that links vision and goals to indicators and assessment } \\
\text { criteria. }\end{array}$ \\
\hline Openness & BP6 & Should make used methods and data accessible to all. \\
\hline Effective Communication & BP7 & There is a need for progress dissemination. \\
\hline Broad Participation & BP8 & $\begin{array}{l}\text { There is a need for broad representation of key grass-roots diverse and } \\
\text { changing values; to ensure the participation of decision-makers. }\end{array}$ \\
\hline Ongoing Assessment & BP9 & Measurements should be repeated in order to evaluate trends. \\
\hline Institutional Capacity & BP10 & $\begin{array}{l}\text { Should be assured by: clearly assigning responsibility and providing } \\
\text { support in the decision-making, providing institutional capacity for data } \\
\text { collection, analysis and documentation. }\end{array}$ \\
\hline
\end{tabular}

Source: Hardi and Zdan(1997) 


\section{Sustainability measurement tools}

For decades, the public considered tourism as the savior of many communities around the world because of its ability to generate new income and jobs. However, many destinations have been caught off-guard in dealing with the impacts of tourism on natural, social, and cultural resources. The unique features ofconventional tourism (non-community based, short-term planning, no protection of natural and human resources, business that brings huge economic benefits and business that has non-ethnical attitude toward environment) increase the need for measurement and transparency in reporting on Triple Bottom Line ideas and lead to strict requirements for tourism in terms of sustainability measurement and reporting.

Taking into consideration the importance of sustainability measurement in all businesses, different institutions have developed measurement tools of TBL ideas. Three most commonlyused sustainability measurement tools are:AIChEBRIDGESworks Metrics, GEMI Metrics Navigator ${ }^{T M}$ andIChemE Sustainability Metrics (Majumdar et al. 2009). This part provides an overview of these tools. Bellagio principles are used to compare these tools and identify their weaknesses. Concluding remarks summarize the results of comparison.

AIChEBRIDGESworks Metrics-In the period between 1999and2004 The American Institute of Chemical Engineers (AIChE) and BRIDGES to Sustainability worked to develop BRIDGESworks Metrics. This metricsis addressed to all businesses with internal decision making and consists of decision rules based on five ratios. The five numerators are: mass of raw materials minus mass of products, potable water used, net energy used, mass of toxins and pollutants. The denominator for each ratio is the output (Majumdar et al. 2009). These ratios concern only two (economic and environmental) out of three Triple Bottom Line spheres (eco-efficiency; Fig. 1). This metric is addressed mostly to production companies and its requirements are mostly not applicable for tourism.

GEMI Metrics Navigator ${ }^{T M}$-AIChE and BRIDGES to Sustainability have developed The Global Environmental Management Initiative GEMI Metrics Navigator ${ }^{\mathrm{TM}}$ as well. This metricsaims to help different types of organizations to create higher quality decision making process towards sustainable development. This is continuous metrics development process consisted of six steps. Each step of the GEMI Metrics Navigator ${ }^{\mathrm{TM}}$ provides suggestions in the form of worksheets, checklist of evaluated criteria and series of questions that differ amongbusinesses. Six-step procedure seems to be applicable in tourism since worksheets and checklists explain the application in non-production sectors.

IChemE Sustainability Metric-Sustainable Development Working Group of The Institution of Chemical Engineers (IChemE) originated from UK has developed theIChemESustainable Development Progress Metrics. This metrics is published for the first time in 2006 and is addressed to different businesses.A number of individuals drawn from industry, consultancy and academia worked on this metrics for three years. They aimed to produce a practical tool for practicing engineers that uses as far as possible information already available (IChemE 2006). Publication introduces a set of economic, environmental and social indicators that are aimed to be used to measure the sustainability 
performance of an operating unit. Metrics contains special requirements for some companies e.g. tourism.

Different economic, environmental and social sustainability criteria have to be measured in companies that use some of sustainable measurement tools(Ricci 2012). Economic criteriaare: Corporate Governance, Risk \& Crisis Management, Codes of Conduct/Compliance/Corruption \& Bribery, Customer Relationship Management and Innovation Management; environmental criteria are: Waste Treatment and Sources of Raw Materials, Pollution Caused by Processes and Products, Risks Arising from Hazardous Chemicals while social criteria are: Human Capital Development, Talent Attraction \& Retention, Corporate Citizenship \& Philanthropy, Occupational Health \& Safety, Labor Practice Indicators and Social Reporting (Ricci 2012). AIChEBRIDGESworks Metrics, GEMI Metrics Navigator ${ }^{T M}$ andIChemE Sustainability Metrics have different requirements for different businesses. However, there provide very strictrequirements for tourism due to its specific features (non-community based, short-term planning, no protection of natural and human resources, business that brings huge economic benefits and business that has non-ethnical attitude toward environment). Further part of paper summarizes special requirements for tourism.

AIChEBRIDGESworks Metrics, GEMI Metrics Navigator ${ }^{T M}$ andIChemE Sustainability Metrics require from companies in all businesses to measure and report progress towards economic criteria. However, tourism has very important role in world's economies. Tourism has experienced rapid growth in the past four decades, and this trend is expected to continue. In 2004 tourism accounts for $10.4 \%$ of the world'sgross domestic product, totaling US\$5.49 billion worth oftotal tourism demand, and employs 214 million peopleworldwide (Chris Choi and Sirakaya, 2005). The forecasts indicate that tourism will grow on average $4.5 \%$ annually between 2005 and 2014. Taking into consideration this fact, the economic sphere of sustainability in tourism is of great importance and all three measurement tools have special treatment in terms of economic criteria for tourism. For example there is special requirement for criteria Innovation Management since tourism is innovation-driven business.

Taking into consideration previously mentioned specific features of tourismmost important issue nowadays in thisbusinessis waste treatment. This issue isconsidered as environmental criteria in (Ricci 2012). All companies that use AIChEBRIDGESworks Metrics andIChemE Sustainability Metrics are obliged to report and measure progress towards reduction of sources of raw materials and pollution caused by its process. IChemE Sustainability Metrics pay much attention on waste treatment in tourism. GEMI Metrics Navigator ${ }^{T M}$ does not observe environmental criteria.

Among three aforementioned measurement tools just IChemE Sustainability Metrics focus on social criteria. IChemE Sustainability Metrics can be used for different businesses as well. Few criteria are obligatory for all businesses (Human Capital Development, Talent Attraction \& Retention, Corporate Citizenship \& Philanthropy, Labor Practice Indicators, Social Reporting). However, Occupational Health \& Safety is obligatory only for tourism. 


\section{CONCLUSION}

This paper aims to describe most commonly used sustainability measurement tools; their special requirements for tourism and to answer the question how tourism contributes to sustainable development. The conclusion states that tourism contributes to sustainable development primarily throughcommunity-driven tourism development; minimization of negative social and cultural impacts; optimization of economic benefits; protection of physical and man-made resources, ethics, policy, standards; visitor satisfaction, maintaining destination attractiveness, use of proper tools and full community participation.

Tab. 2. Measurement tools of sustainable development (comparison)

\begin{tabular}{|c|c|c|c|}
\hline $\begin{array}{l}\text { Bellagio } \\
\text { principle }\end{array}$ & $\begin{array}{l}\text { BRIDGESworks } \\
\text { Metrics }\end{array}$ & GEMI Metrics Navigator & $\begin{array}{l}\text { IChemE Sustainability } \\
\text { Metrics }\end{array}$ \\
\hline BP1 & Yes & Yes & Yes \\
\hline BP2 & $\begin{array}{c}\text { Limited social aspects are } \\
\text { considered }\end{array}$ & $\begin{array}{c}\text { Optional whether the 3 pillars } \\
\text { of TBL are included }\end{array}$ & $\begin{array}{c}\text { Includes 3 pillars of TBL but } \\
\text { social is narrowly defined }\end{array}$ \\
\hline BP3 & No & Optional & Narrowly defined \\
\hline BP4 & No & Optional & No \\
\hline BP5 & Yes & Yes & Optional \\
\hline BP6 & Optional & Optional & Optional \\
\hline BP7 & Optional & Optional & $\begin{array}{c}\text { Limited to employees and } \\
\text { local community }\end{array}$ \\
\hline BP8 & Optional & Optional & No \\
\hline BP9 & Optional & Yes & Yes \\
\hline BP10 & Yes & \multicolumn{2}{|c|}{}
\end{tabular}

Source: Majumdar et al. (2009)

Three most commonly used tools for businesses are:AIChEBRIDGESworks Metrics, GEMI Metrics Navigator ${ }^{T M}$ andIChemE Sustainability Metrics. This paper shows these measurement tools have some common requirements for different businesses. However, requirements for tourismare very strict since it is considered as non-community based, short-term planning, no protection of natural and human resources, business that brings huge economic benefits and business that has non-ethnical attitude toward environment.

Different methodologies are used in order to identify most suitable tool. One of them is Bellagio framework. As a concluding remark of this paper there is the comparison ofthree aforementioned tools following Bellagio framework (Tab.2).

Analysis indicates that all of three tools have some weaknesses. AIChEBRIDGESworks Metrics does not consider equitable access to resources; care of future generations and social sphere. Weaknesses of GEMI Metrics Navigator ${ }^{\mathrm{TM}}$ are: stakeholders are not consulted; impact on future generations isignored;no transparency. Weaknesses of IChemE Sustainability Metric are: large number of indicators; indicators are not available for stakeholders; no transparency; social indicator is analyzed in limited range (Majumdar et al. 2009). Taking into considerationthe weaknesses of aforementionedtools, there is a need for further development of sustainabilitymeasurement tools in tourism. 


\section{REFERENCE LIST}

1. Azapagic, A. \&Perdan, S. (2000). Indicators of sustainable development for industry: a general framework. Trans IChemE, Vol 78, 243-261.

2. Becker, J. (2004). Making sustainable development evaluations work. Sustainable Development, Vol 12, 200-211.

3. Berlin Declaration (1997). The Berlin Declaration on Biological Diversity and Sustainable Tourism. International Conference of EnvironmentMinisters on Biodiversity and Tourism. March 6-8. Berlin, Germany:United Nations

4. Chris Choi, H.S. \&Sirakaya, E. (2005). Measuring residents' attitude toward sustainable tourism: development of sustainable tourism attitude scale. Journal of Travel Research, Vol 43, 380-394.

5. Hardi, P. and Zdan, T. (1997). Assessing sustainable development: principles in practice. International Institute for Sustainable Development.

6. Hoff, M. D., ed. (1998). Sustainable Community Development: Studies in Environmental, Economic and Cultural Revitalization. Boca Raton,FL: Lewis.

7. IChemE - The Institution of Chemical Engineers. (2006). The sustainability metrics. Retrieved June 21, 2015, from

http://nbis.org/nbisresources/metrics/triple_bottom_line_indicators_process_indust ries.pdf.

8. Majumdar, J., Bhasin, V. \&Jollands, M. (2009). Sustainability tools for the chemical industry, In Australian Life Cycle Assessment Society Inc (Ed.), Proceedings of the 6th Australian Conference on Life Cycle Assessment, (pp. 1-7). Melbourne, Australia.

9. McGahey, S. (1996). "Tourism: The Multiplier Effect and Leakage." Available at from http://www.uog.edu/sbdc/journals (accessed April 28, 2003).

10. McIntyre, G. (1993). Sustainable Tourism Development: Guide for Local Planners. Madrid, Spain: World Tourism Organization.

11. Morris, V., Shopley, J.\& Turner, E. (1998). The role of metrics in sustainable development: a progress report. Arthur D Little, Vol 74, 24-30.

12. Ricci, A. (2012). Sustainability in the chemical industry. SAM sustainability investing, Vol 3, 1-10.

13. Rossi, R. J., and K. J. Gilmartin (1980). The Handbook of Social Indicators:Source, Characteristics, and Analysis. New York: Garland STPM.

14. Rowe, J. S. (1992). The ecosystem approach to forestland management. The Forestry Chronicle, Vol 682, 222-24.

15. Sharpley, R., and J. Sharpley (1997). Sustainability and the consumption of tourism. In Tourism and Sustainability: Principles to Practices, edited by M. J. Stabler. New York: Cab International, pp. 231-243.

16. Sikdar, S.K. (2003). Sustainable development and sustainability metrics.AIChE Journal, Vol 49, 1928-1932.

17. Székely, F. \&Knirsch, M. (2005, October). Leadership and corporate responsibility metrics for sustainable corporate performance. Retrieved June 15, 2015, from http://www.esmt.org/fm/13/Working\%20Paper_Metrics.pdf

18. Veenhoven, R. (2001). Why Social Policy Needs Subjective Indicators. Berlin, Germany: Social Science Research Center. 